\title{
Engineering-geological investigation in the coastal zone of St. Anastasia Island
}

\section{Dimitar Dimitrov}

Institute of Oceanology, Bulgarian Academy of Sciences, Department of "Marine Geology and Archaeology”; e-mail: dimpetdim@io-bas.bg, dimpetdim@yahoo.com

\section{Инженерногеоложки изследвания в акваторията на остров Света Анастасия}

\author{
Димитьр Димитров
}

Dimitrov, D. 2019. Engineering-geological investigation in the coastal zone of St. Anastasia Island. Engineering Geology and Hydrogeology, 33, 67-75.

\begin{abstract}
The Engineering-geological research relates to the development of concepts for the reconstruction and extension of an existing harbor for small vessels on St. Anastasia Island in order to protect the water area from dangerous geological and meteorological conditions. It is confirmed that in connection with the construction of future hydrotechnical facilities, the studied area is presented of Upper Cretaceous volcanic rocks and Quaternary marine sediments, subjected to the active impact of lithodynamic processes in Burgas Gulf. The performed Engineering geological studies included sampling, sample analysis, strength-deformation and physico-mechanical characteristics of lithological varieties and foundation conditions. The conditions for the foundation of the designed pier with a fenced mall are favorable for two types of hydrotechnical constructions: gravity and pilot.

Keywords: Burgas Gulf, St. Anastasia Island, marine sediments, Upper Cretaceous, Quaternary, Engineering geological conditions.
\end{abstract}

Резюме. Настоящото изследване е свързано с изготвяне на концепции за реконструкция и разширяване на съществуващ пристан за малки плавателни съдове на остров Света Анастасия с цел защита на акваторията от опасни геоложки и метеорологични условия. Проведените инженерногеоложки проучвания включваха вземане и селекция на проби, анализ на пробите, якостно-деформационни и физико-механични характеристики на литоложките разновидности и условията на фундиране. Условията за фундиране на проектирания пристан с ограден мол са благоприятни за два типа хидротехнически конструкции: гравитационна и пилотна.

Ключови думи: Бургаски залив, остров Света Анастасия, морски седименти, горна Креда, Кватернер, инженерногеоложки условия.

\section{Въведение}

Настоящото изследване е свързано с изготвяне на концепции за реконструкция и разширяване на съществуващ пристан за малки плавателни съдове на остров Света Анастасия. Целта е да се предвидят различни видове природни рискове и опасности, застрашаващи строителството на бъдещите хидротехнически съоръжения като: рискови океанографски фактори, климатични явления, рискови геоложки процеси и др. „Островът” е един от символите на културнотоисторическо наследство на Р. България (Karaijotov, 2004). 


\section{Геоморфоложка характеристика}

Остров Света Анастасия е разположен в южната част на Бургаския залив, между носовете Чукаля и Атия с географски координати 42 $28^{\prime} 07.492$ '” $\mathrm{N}, 027^{\circ} 33^{\prime}$ 06.247 ' Е (фиг. 1, 2, 3). Намира се на 6,5 km югоизточно от гр. Бургас. Островът е един от седемте български острова в Черно море и третият по големина след островите Свети Иван и Свети Кирик с площ $0,01 \mathrm{~km}^{2}$.

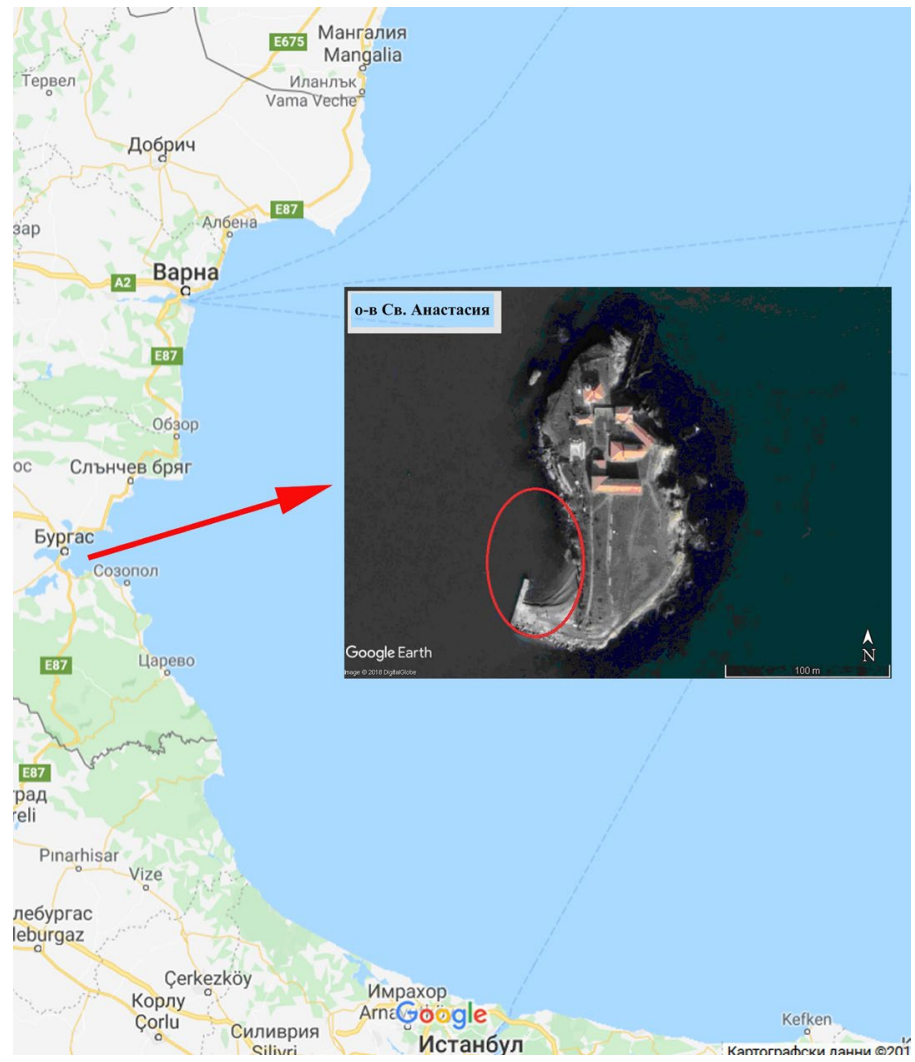

Фиг. 1. Остров Св. Анастасия с приблизителни граници на акваторията на бъдещия пристан за малки плавателни съдове (Google Earth, 2018)

Fig. 1. St. Anastasia Island and borders of the future harbor for small boats (Google Earth, 2018)

\section{Геолого-тектонски строеж}

Геоложкият строеж на участька е тясно свързан с най-новата геоложка история на черноморския басейн (Peychev, 2004; Peychev, Dimitrov, 2010; Peychev, Dimitrov, 2011; Georgiev et al., 2012; Dimitrov et al., 2018). След регресията на сарматския басейн, вследствие на тектонски колебателни движения, релефът на Бургаската низина е бил подложен на интензивна денудация и по тази причина сарматски седименти са запазени само северно от кв. Сарафово и южно от с. Приморско.

Впоследствие върху неравния денудиран сарматски релеф се отлагат седиментите на плиоценския басейн, които имат езерен фациес. Отложили са се предимно глини с прослойки и лещи от песъчливо-глинести и варовито-песъчливи материали. След проявата на позитивни вертикални движения плиоценските отложения се издигат и се оформят като суша. Започва засилена плоскостна денудация, в резултат на която горнището на плиоцена придобива заоблени форми. 


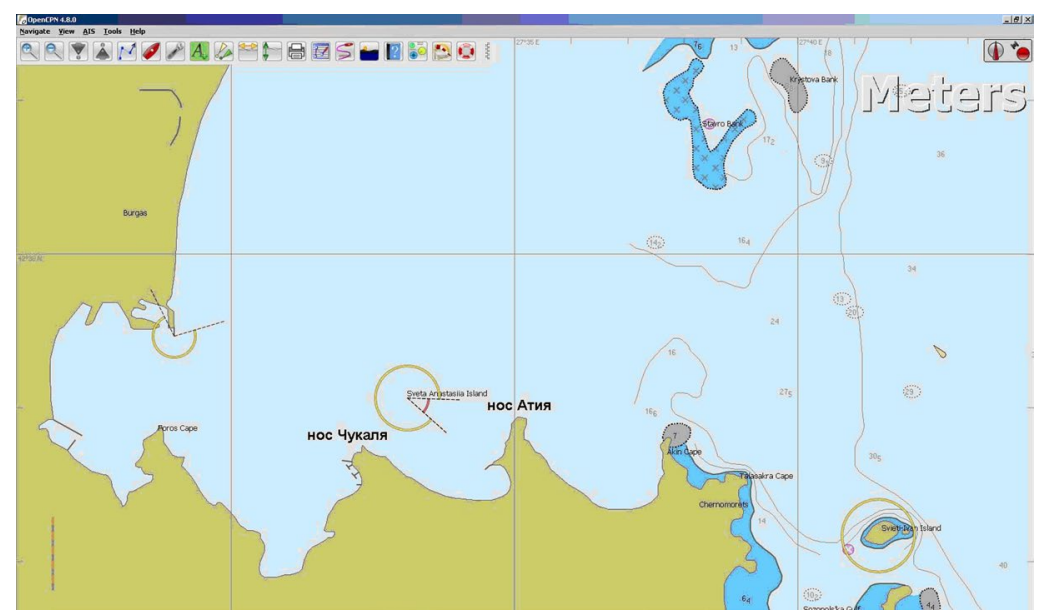

Фиг. 2. Навигационна карта на изследвания участък, (OpenCPN 4.8.0, 2017)

Fig. 2. Navigation map of the investigation area, (OpenCPN 4.8.0, 2017)

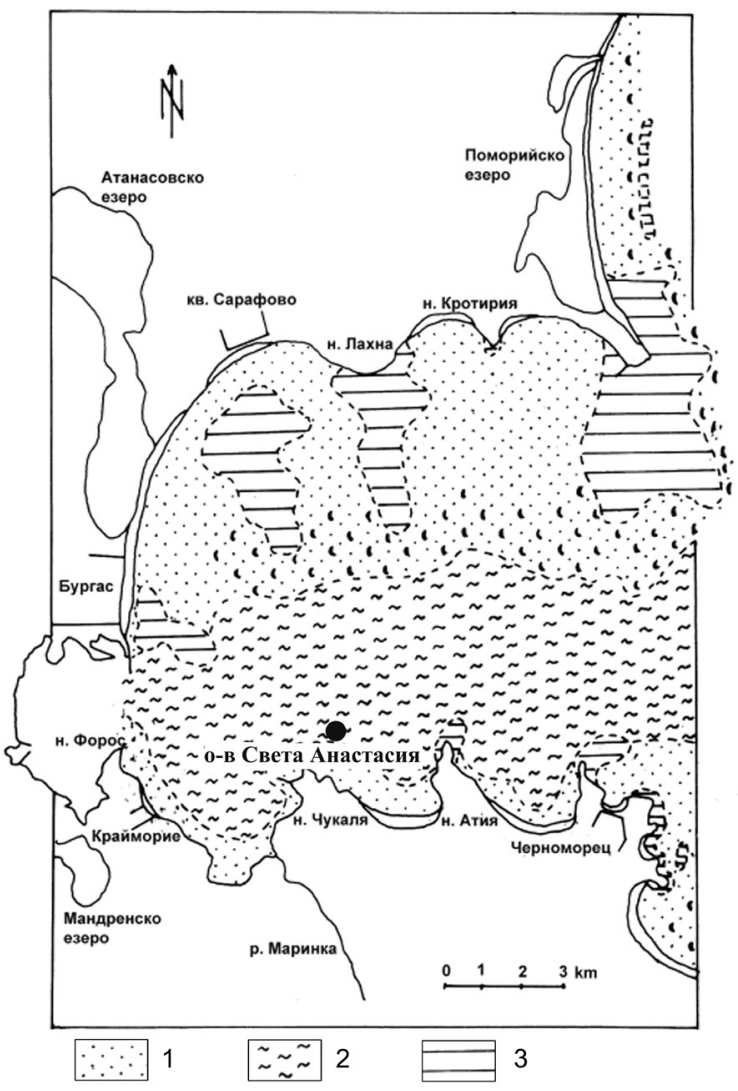

Фиг. 3. Картосхема на морските седименти в Бургаския залив (Peychev, Dimitrov, 2012) 1 - пясъци с мидени включения, 2 - тини и глини, 3 - скалисто дъно

Fig. 3. Map of the marine sediments in the Burgas Gulf (Peychev, Dimitrov, 2012) 1 - sands, including crushed mussel shells, 2 - mud and clays, 3 - rocks 
На границата Плиоцен-Плейстоцен се появява трансгресия, започнала с отлагане на чакълесто-глинести утайки и върху тях - на кафяви глини. През холоцена вертикалните движения на земната кора приемат негативен характер и крайбрежието потъва, като се образуват лиманни езера в удавените речни долини - Атанасовско, Бургаско, Мандренско, които са отделени от морето с пясъчни коси. През плейстоцена настъпва постепенно изместване на оста на синклиналата, която през холоцена се доближава почти до сегашния южен бряг на залива по направление на оста на Мандренското езеро. Това всъщност е била и оста на долината на реките Русокастренска и Средецка, която интензивно е потънала в началото на Вюрма и сега е запълнена до 40 - 50 m с морски тинести наслаги. Потъването на морския бряг продължава и понастоящем със скорост около 1,5 mm/y. Същевременно, вследствие глобалното затопляне на климата, се повишава и морското ниво със скорост 2 mm/y (Peychev, Dimitrov, 2012).

Крайбрежните морски тераси в района на Бургаската депресия са с холоценска възраст и са изградени от средни пясъци, глинести пясъци, песъчливи глини и глини с основни минерали монтморилонит, каолинит, илит, кварц, плагиоклази, авгит и магнетит.

След понижаване на низината по време на Кватернера (края на Вюрм), вследствие заливането на низината от морето са се получили съвременните морски наслаги: пясъци с мидени включения и тини (фиг. 3) (Peychev, Dimitrov, 2012).

Регионът на остров Света Анастасия в тектонско отношение е част от Бургаската депресия, която е изпълнена от горнокредни аргилитни и карбонатни седименти и вулканогенни скали с обща дебелина $2-3 \mathrm{~km}$. В нейната южна част е разположен Росенският плутон, съставен от монцодиорити, монцонити и сиенити.

В участька са разположени обширните лимани - Атанасовско езеро, с площ $25 \mathrm{~km}^{2}$ и Бургаско - Мандренския лиман с площ $109 \mathrm{~km}^{2}$, които са отделени от морето с широки и дълги плажове.

Южно от н. Форос по Българското черноморско крайбрежие преобладават разкрития на вулканогенни скали от Бургаската група, които имат горнокредна възраст. Носовете Форос и Чукаля са изградени от калиево-алкални трахити. Между н. Чукаля и н. Атия се срещат лавови потоци от калиево-алкални трахити и калиево-алкални мелатрахити, базалти и андезитобазалти, а при носовете Атия, Акин и Хрисосотира се разкриват меланократни калиево-алкални сиенити и кварцосъдържащи сиенити (с кварцово съдържание 10 - 15\%) (Petrova et al., 1994 a,b), (фиг. 4).

Средният наклон на подводния брегови склон е 0,01, като в северната част на Бургаския залив той е по-малък, отколкото в южната. В южната част скални банки се разкриват непосредствено пред носовете Форос, Атия, Акин и Таласакра. Пред плажовете са разпространени среднозърнести и дребнозърнести пясъци. В централната и южна част на залива са отложени алевритови тини.

Брегьт в акваторията на залива на съществуващия пристан е с височина 3 - 9 m. Дъното на залива е покрито от чакълести едри пясъци с дебелина 0,15 $1,0 \mathrm{~m}$.

В района се наблюдава горнокреден $\left(\mathrm{K}_{2}\right)$ и холоценски (1Qh и $\left.\mathrm{mQh}\right)$ седиментни комплекси с голяма дебелина.

Нос Атия е изграден от алкални и кварцосъдържащи сиенити. Нос Чукаля и остров Света Анастасия са изградени от вулканитите на Равногорската свита $\left(\operatorname{rgK}_{2}\right)$. Свитата е представена от туфи и лави на алкални трахити (българити). Равногорската свита се разполага върху Карталкуската свита $\left(\mathrm{ktK}_{2}\right)$, която е представена от туфи и лави на алкални базалтоиди. 


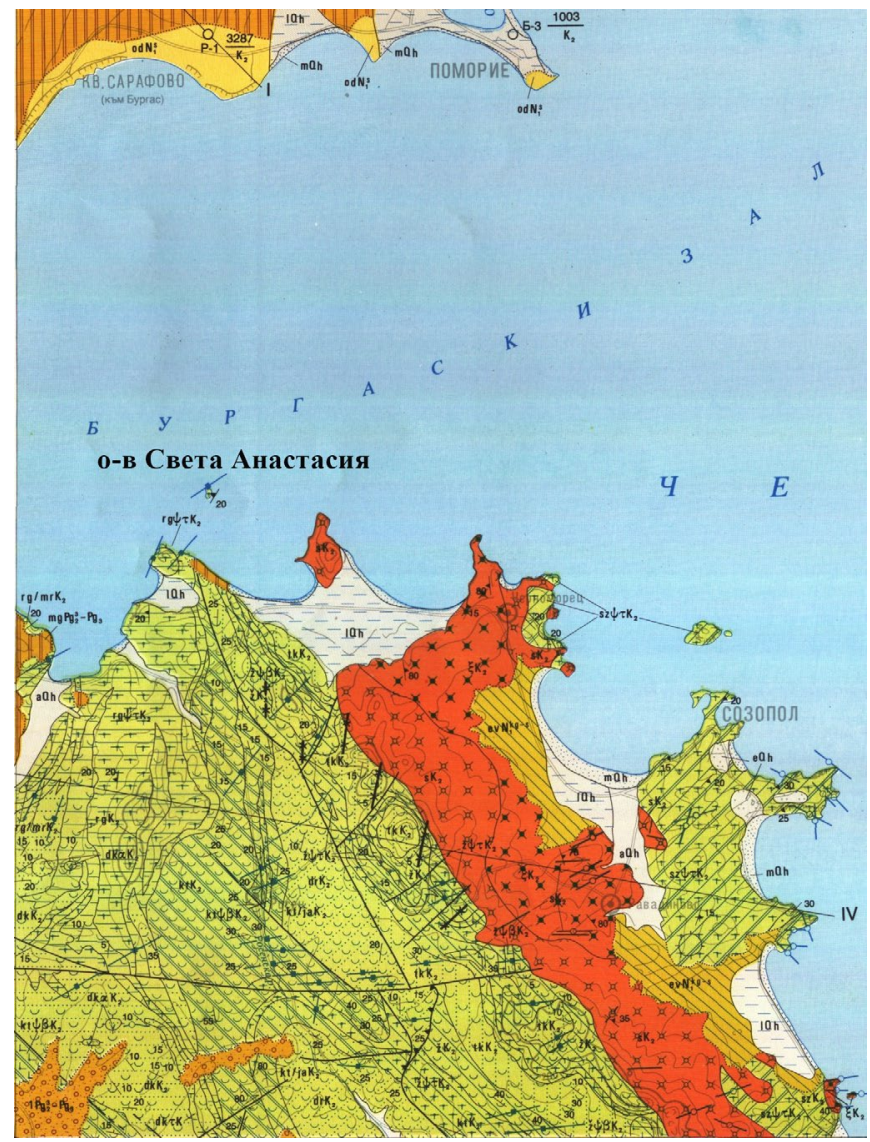

Фиг. 4. Геоложка карта на изследвания участьк (Petrova et al., 1994a)

$\mathrm{ktK}_{2}$ - Карталкуска свита, $\mathrm{rgK}_{2}$ - Равногорска свита, $1 \mathrm{Qh}$ - езерни седименти, $\mathrm{mQh}$ - морски седименти Fig. 4. Geological map of the investigation area (Petrova et al., 1994a)

$\mathrm{ktK}_{2}$ - Kartalkuska Formation, $\mathrm{rgK}_{2}$ - Ravnogorska Formation, $1 \mathrm{Qh}$ - lake sediments, mQh - marine sediments

В тектонско отношение районът се намира между Бургаската депресия и Росенския плутон. Това е в съответствие с изготвения сеизмотектонски модел на Българския сектор на Черно море от Dimitrov et al. (2005). Отражение върху неговото развитие дават неотектонските движения, които водят до изменения на ерозионния базис. Съвременните колебателни тектонски движения на земната кора в Бургаския залив са негативни със скорост на потъване 1,46 mm/y.

\section{Инженерно-геоложка характеристика}

За изясняване на геолого-литоложкия строеж на участька, на физико-механичните и якостно-деформационните характеристики на литоложките разновидности и на условията на фундиране са използвани данни от Georgiev et al. (2012), данни от картировъчни шурфове, както и от лабораторни изпитвания на земни проби.

С направените проучвателни изработки са установени следните литоложки разновидности:

Литоложка разновидност № 1 - Холоцен (mQh) - чакълести, едри и средни пясъци, равнозърнести с включения от натрошени мидени черупки предимно от Mytilus galloprovincialis; 
Литоложка разновидност № 2 - горна Креда $\left(\mathrm{rgK}_{2}\right)$ - горнокредни вулканити.

\section{Физични и якостно-деформационни характеристики на литоложките разновидности}

Литоложка разновидност № 1 - Холоцен - чакълести, едри и средни пясъци (БДС EN ISO 14688-2) с включения от натрошени мидени черупки (фиг. 5) предимно от Mytilus galloprovincialis. Физичните им показатели са следните:

- Обемна пльтност, $\rho_{\mathrm{n}}=1,81 \mathrm{~g} / \mathrm{cm}^{3}$

- Специфична плътност, $\rho_{\mathrm{s}}=2,75 \mathrm{~g} / \mathrm{cm}^{3}$

- Обем на порите, $n=0,51$

- Коефициент на порите, $e=1,04$.

Зърнометричният състав е представен на фиг. 6. Наименованието на почвата е определено по Еврокод чрез триъгълна диаграма (БДС EN ISO 14688-2) - grSa чакълест Пясък, равнозърнест. Трябва да се отбележи, че по-голямата част от чакълестата фракция е за сметка на натрошените мидени черупки.

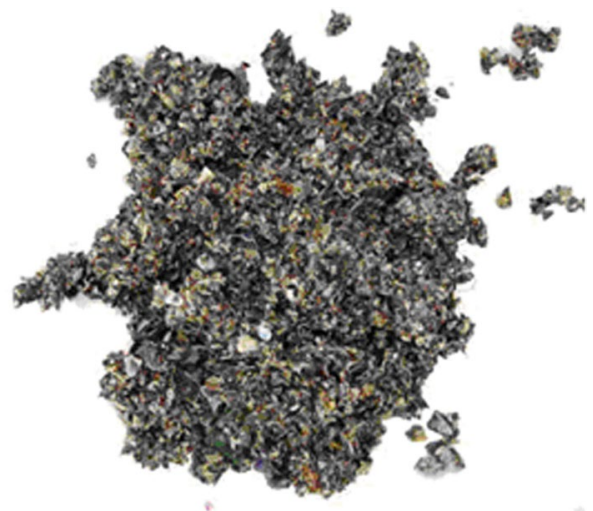

Фиг. 5. Проба от акваторията на остров Света Анастасия - чакълести, едри и средни пясъци с включения от натрошени мидени черупки

Fig. 5. Sample from coastal zone of St. Anastasia Island - gravelly, coarse and medium-sized sands, including crushed mussel shells

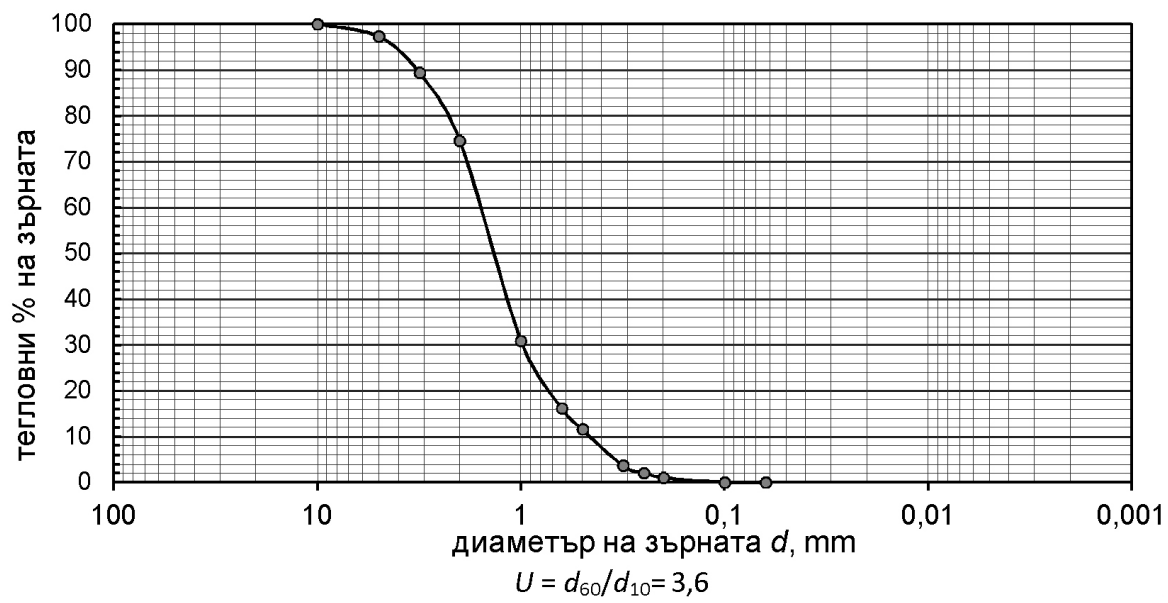

Фиг. 6. Зърнометрична крива на литоложка разновидност № 1

Fig. 6. Particle size distribution of the sample 1 
Якостните и деформационни характеристики на литоложка разновидност № 1 се дават въз основа на лабораторно директно изпитване.

- Кохезия, $c=4,7 \mathrm{kN} / \mathrm{m}^{2}$

- Ђгъл на вътрешно триене, $\varphi=43,7^{\circ}$

- Оедометричен (компресионен) модул при $200 \mathrm{kPa}, E_{\text {oed200 }}=4,6 \mathrm{MPa}$

- Оедометричен (компресионен) модул при $300 \mathrm{kPa}, E_{\text {oеd200 }}=6,2 \mathrm{MPa}$

Литоложка разновидност № 2 - горна Креда - горнокредни вулканити. Физичните им показатели са следните:

- Обемна пльтност, $\rho_{\mathrm{n}}=2,78 \mathrm{~g} / \mathrm{cm}^{3}$

\section{Физико-геоложки явления}

От физико-геоложките явления в участька е проявена морската абразия (Bruchev et al., 1994). За активизирането на абразията способства и литоложкият строеж на брега, който е изграден от силно променени, изветрели и напукани вулканити (фиг. 7).

Морските вълни активно размиват вулканските скали, като отнасят в дълбочина глинестата и праховата фракция от него и на плажа се отлага само чакълест пясък.

Съгласно "Норми за проектиране на сгради и съоръжения в земетръсни райони" проучваният район е VII сеизмична степен по скалата на МедведевШпонхойер-Карник с коефициент на сеизмичност $K c=0,10$.

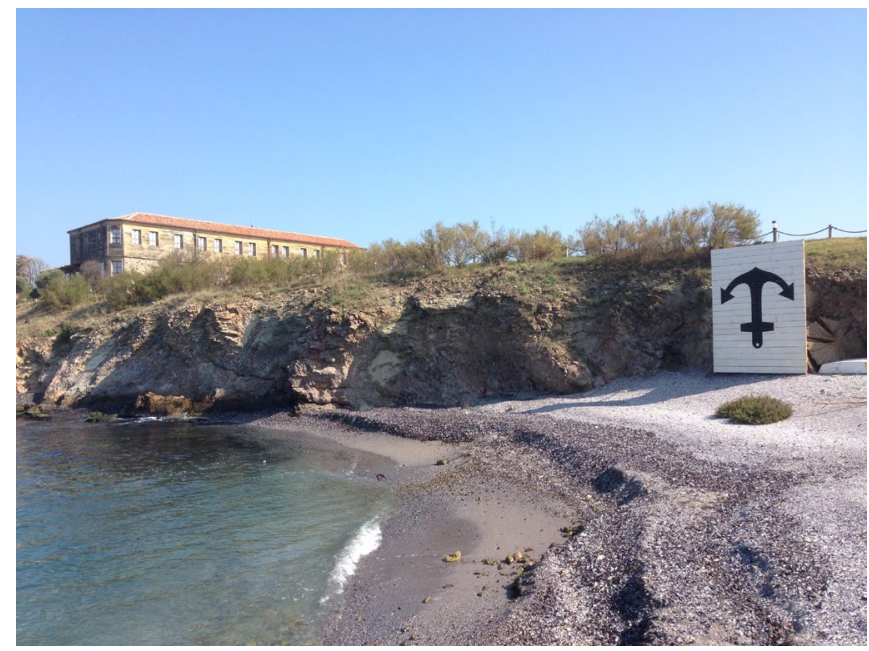

Фиг. 7. Абразионна и акумулационна морска тераса в района на изследвания участък

Fig. 7. Erosion and accumulation marine terrace in the investigation area

\section{Заключение и препоръчителни условия на фундиране}

От направените проучвания и взетите проби са установени следните литоложки разновидности:

Литоложка разновидност № 1 - Холоцен - чакълести, едри и средни пясъци с включения от натрошени мидени черупки предимно от Mytilus galloprovincialis.

Литоложка разновидност № 2 - горна Креда - горнокредни вулканити.

Брегът на изследвания участък е изграден от силно променени, изветрели и напукани горнокредни вулканити, които сравнително лесно се размиват от морската абразия. След като се подготвят микроскопски препарати от скалните 
образци ще е възможно да се определи видът на скалата и свитата, към която принадлежи.

При строителството на бъдещите хидротехнически съоръжения е изключително важно да се имат предвид някои рискови океанографски фактори (вълнение, морски течения), рискови геоложки процеси (абразия, свлачища, срутища и тектонски процеси), климатични явления (резки промени на температурата на морската вода и въздуха, ветрове) и химични фактори (агресивност на морската вода спрямо брегозащитните съоръжения и фундаментите на бъдещите хидротехнически съоръжения).

Условията за фундиране на проектирания пристан с ограден мол са благоприятни за два типа хидротехнически конструкции: гравитационна и пилотна.

Повърхностният пясъчен слой може лесно да бъде преодолян при пилотни конструкции до достигане на долния скален пласт; при гравитационни - същият може да се използва като постилаща основа на каменната възглавница, върху която лягат стоманобетонните елементи. Поради агресивността на морската вода спрямо бетона строго се препоръчва използването на сулфатоустойчив бетон.

При избор на вариант с пилотно фундиране, върховете на пилотите (долният им край, с който стьпват) ще залягат в здрава скална основа, което предполага изпълнение на изливни пилоти in situ. Последните могат да бъдат с или без обсадна тръба в зависимост от здравината на скалната основа.

„Островът” е културен и исторически центьр не само за община Бургас но и за Българското черноморско крайбрежие. Това поражда необходимостта от опазването и изучаването на културното-историческо наследство и разпространението му като част от общата европейска културна традиция и история.

\section{Използвани нормативни документи}

1. Закон за морските пространства, вътрешните водни пътища и пристанищата на Република България (ДВ. бр.12 от 11 февруари 2000г.,... изм. ДВ. бр.23 от 22 Март 2011г.).

2. Наредба № 9 от 29 юли 2005 г. за изискванията за експлоатационна годност на пристанищата (ДВ. бр.65 от 9 Август 2005 г.,... изм. ДВ. бр.103 от 7 Декември).

3. Наредба № 1 от 01.09.96 г за проектиране на плоско фундиране (ДВ, бр, 85 от 8 октомври 1996).

4. Норми за проектиране на сгради и съоръжения в земетръсни райони. (ДВ, бр. 68 от 2007 г.).

5. Правила за приемане на земни работи и земни съоръжения. БСА, кн. 6. 1988 г.

6. Норми за проектиране на фундаменти подложени на динамични товари от машини (БСА, кн. 2, 1986).

7. Еврокод 7. 2010. Геотехническо проектиране. Изд. на БИС. С. 196 с.

\section{Благодарности}

Авторът изказва благодарност на колегите от ГИ-БАН за оказаното съдействие и на колегите от община Бургас за предоставените архивни материали, свързани с подготовката на настоящата статия.

Статията е подготвена и във връзка с изпълнението на Национална научна програма (ННП) „Опазване на околната среда и намаляване на риска от неблагоприятни явления и природни бедствия“", одобрена с Решение на МС № 577/17.08.2018 г. и финансирана от МОН (Споразумение № Д01-230/06.12.2018 г.). 


\section{Литература}

\section{References}

Bruchev I. (ed.) et al. 1994. Geological Hazards in Bulgaria. Publishing House of the Bulgarian Academy of Sciences. 143 p. (In Bulgarian, with English Abstract).

Georgiev, G., V. Peychev, D. Dimitrov. 2012. Engineering-geological, hydrodynamical and lithodynamical conditions and solutions for the Sarafovo fishing port. Scientific Almanac of Varna Free University, series "Architecture and Construction”, vol. 6, 269-280 (In Bulgarian).

Google Earth, 2018. https://www.google.com/earth/

Dimitrov, D., R. Hristova, V. Peychev. 2018. Geological and geomorphological characteristics of Miocene and Quaternary marine sediments in coastal zone of the region "Karantinata" in Varna gulf. SocioBrains, Issue 41, 169-173.

Dimitrov, O., S. Shanov, I. Genov, A. Boykova. 2005. Earthquake Risk for Town of Varna. International Symposium on Latest Natural Disasters - New Challenger for Engineer Geology, Geotectonic and Civil Protection, September 5-8, Sofia, Bulgaria, 1-12.

Karaijotov, I. 2004. Island "St. Anastasia". 136 p. (In Bulgarian).

OpenCPN 4.8.0. 2017. https://opencpn.org/OpenCPN/about/ver480.html

Peychev, V. 2004. Morphodynamical and lithodynamical processes in the coastal zone. Slavena, Varna, 231 p. (In Bulgarian, with English Abstract)

Peychev, V., D. Dimitrov. 2010. Engineering-geological and hydrodynamical conditions in the coastal zone of the "Marina-Nessebar". Intern. Conf. of Civil Engineering Design and Construction and Application of Eurocodes (Science and Practice). Varna, 441-445.

Peychev, V., D. Dimitrov. 2011. Engineering-geological and hydrological conditions in the coastal zone of the "Marina Sozopol" port. Scientific Almanac of Varna Free University, series "Architecture and Construction", vol. 5, 93-102 (In Bulgarian).

Peychev, V., D. Dimitrov. 2012. Oceanology. Varna, „Ongal”. 493 p. (In Bulgarian).

Petrova, A., L. Mihailova, V. Vasileva. 1994a. Geological map of Bulgaria on Scale 1:100 000. Pomorie Map Sheet. Geology and Mineral Resources Committee, Enterprise of Geophysical Survey and Geological Mapping.

Petrova, A., L. Mihailova, V. Vasileva. 1994b. Explanatory note to the Geological Map of the Republic of Bulgaria on Scale 1:100 000. Pomorie Map Sheet. Geology and Mineral Resources Committee, Enterprise of Geophysical Survey and Geological Mapping, $39 \mathrm{p}$.

Постьпила: 25.10 .2019

Приета: 11.12.2019
Received: 25 October 2019

Accepted: 11 December 2019 
76 Geological Institute, Bulgarian Academy of Sciences C 